\title{
Nanotechnology enabled management approaches against the Covid-19 pandemic
}

\author{
Devasena T' ${ }^{1}$, Akriti Sharma ${ }^{2}$ and Rama Shanker Verma ${ }^{2 *}$ \\ ${ }^{1}$ Centre for Nanoscience and Technology, Anna University, Chennai 608002, India \\ ${ }^{2}$ Stem Cell and Molecular biology Laboratory, Department of Biotechnology, Indian Institute of Technology Madras, Chennai-600036 Tamil Nadu, India
}

\begin{abstract}
COVID-19 has been the causative virus for one of the biggest pandemic in human history and is still a major threat to human health after more than a year of its first incidence. Since its outbreak, it fueled a worldwide demand for the following: i) rapid, predictive and sensitive diagnostic tool ii) specific vaccine candidate and targeted prevention iii) effective anti SARS CoV2 therapy and personalized medicine. Different fields of science and technology have contributed in this battle against coronavirus. Nanotechnology has also played a crucial role in making technologically advanced equipment and devices, breaking bottlenecks in facing the pandemic. Deeper insights regarding interface between nanotechnology and coronavirus can further direct the scientists and researchers towards a new era for the impeccable design and repurposing of drugs, vaccines and detection method for COVID-19. Entering the era of Nanotechnology-SARS CoV2 interface will not only be critical in counteracting COVID-19 but also be vital in the management of future pandemics. Hence, our review systematically correlated the SARS-CoV2 structure, life cycle and proteomic antigenicity with the potential drugs, vaccines, diagnostic and management strategies with a special emphasis on the existing and promising role of nanotechnology. This review offers a reference for future studies and guide researchers for the translation of nanotechnological concepts into effective theranostic and management strategies and support our fight against the current and the future coronavirus pandemics.
\end{abstract}

\section{Introduction}

Coronaviruses (COVs) has been established as pathogenic virus to animals and mildly infective to humans in 1937. There are four genera of CoVs, namely, alphacoronavirus $(\alpha \mathrm{CoV})$, betacoronavirus $(\beta \mathrm{CoV})$, deltacoronavirus $(\delta \mathrm{CoV})$, and gammacoronavirus $(\gamma \mathrm{CoV})$ [1]. In 2002-2003, there was an outbreak of the severe acute respiratory Syndrome (SARS) pandemic which killed approximately 900 people in a few months. The causative agent was identified as a positive strand RNA virus, classified as a member of the $\beta$ coronavirus genera lineage A (so called SARS-COV) and its genome was sequenced [2]. Later, the Middle East Respiratory Syndrome was known to be caused by MERS$\mathrm{CoV}$ which are betaCoVs. Thereafter, research on SARS COV has become more intense globally leading to many research articles and patents $[3,4]$.

By December 2019, the World Health Organization (WHO) was informed of cases of pneumonia of unknown cause in Wuhan City, Hubei Province, China. This epidemic, which started on 12th December 2019, had caused 95.5 million laboratory-confirmed infections including more than 2 million deaths by January 2021 [5]. Case history of the patients revealed symptoms like fever, malaise, dry cough, and dyspnoea with a positive titre of a novel Coronavirus (nCoV-19). nCOV-19 is capable of producing severe lower respiratory tract infection with acute respiratory distress syndrome and extrapulmonary manifestations such as diarrhoea, lymphopenia, deranged liver and renal function tests, and multi-organ dysfunction in both immunocompetent and immunocompromised host cells [6,7].

The International Committee on Taxonomy of Viruses (ICTV) termed the novel virus which caused the pandemic as the SARS-CoV2 virus as it is very similar to the one that caused the SARS outbreak (SARS-COV) and also belongs to the same category of $\beta$ coronavirus genera lineage A. Cryo-electron microscope reveals that SARS-CoV2 is spherical or elliptic with a diameter of approximately 70-90 $\mathrm{nm}$ [8]. In addition, the WHO has released the official name of the disease caused by this virus as COVID-19 [9].

Recently, Chan, et al. (2020), reported the Genomic character of the SARS CoV-2 isolated from a patient with atypical pneumonia after visiting Wuhan [10]. Full genome characterization of the samples obtained from patients at an early stage of the COVID-19 outbreak reveals that SARS-CoV2 and SARS-CoV belong to the same species [5]. In this crisis, a collective pool of knowledge about various aspects of SARS CoV2 and COVID-19 is a prerequisite for researchers, academicians and scientists. Chan, et al. emphasize that nanotechnology concepts can be a frontline to fight against COVID-19 in terms of nanotheranostics and management tools. A number of research targets for the nanotechnology community has rightly been pointed out in this article [11]. Evidences from bibliographic analysis confirms meagre number of publications and patents on coronavirusnanotechnology interface $[12,13]$.

Hence, this article will elucidate the nanotechnology-SARS-CoV2 interface. This interfacial approach will afford a reference for future studies and guide researchers for the rational design of effective theranostic and management tools and support our fight against the current and the future coronavirus pandemics.

${ }^{\star}$ Correspondence to: Verma RS, Prof., Head, Stem cell and Molecular Biology Laboratory, Bhupat and Jyoti Mehta school of Biosciences, Department of Biotechnology, IIT-Madras Chennai-600036, Tamil Nadu, India Tel: 0442257 4109; Email: vermars@iitm.ac.in

Key words: Covid-19, Nanotechnology, Nano drugs, Diagnostic tools

Received: January 08, 2021; Accepted: April 13, 2021; Published: April 16, 2021 


\section{Structural proteins contribute to antigenicity of SARS- COV2}

SAR-CoV2 is an enveloped, non-segmented, RNA virus with a diameter 70-90 nm [8]. Proteins and RNA genome are the structural components of SARS CoV2 involved in host interaction and infection [14]. Altogether, the structural components of COVID-19 virus contribute to virulence and several complex immune-evasion [15] (Figure 1)

SARS-CoV-2 has four main structural proteins: spike (S) glycoprotein, small envelope (E) glycoprotein, membrane (M) glycoprotein, and nucleocapsid $(\mathrm{N})$ protein, and also several accessory proteins. The role of these structural proteins [16] are summarized in Table 1.

The $\mathrm{S}$ protein project outwards from the viral envelope giving a crown like appearance. The spike is a homotrimer transmembrane protein (molecular weight $=150 \mathrm{kDa}$ ). It facilitates binding of the envelope to the host cell receptor-angiotensin-converting enzyme 2 (ACE2) expressed in lower respiratory tract cells. Thus, $\mathrm{S}$ protein plays a significant role in antigenicity. $S$ protein has two subunits, S1 and S2 cleavable by furin-like proteases. S1 has a signal peptide which mediates viral binding via S1's receptor binding domain (RBD comprising of 318 - 510 amino acid residues) and release into host cytoplasm. S1 subunit of SARS-Cov2 shares $70 \%$ identity to that of the human SARS CoV. S2 functions to mediate virus fusion during host transmission. It was demonstrated that SARS CoV2 and SARS CoV bind with similar affinities to ACE2 and that SARS CoV polyclonal antibodies inhibit SARS-CoV2 spike-mediated entry into cells. This emphasizes that the cross-neutralizing antibodies targeting conserved $S$ epitopes (antigens) can be elicited upon vaccination [17]. S protein can exist in two structurally different forms, prefusion conformation and post fusion conformation. S1 is involved in attachment to host receptor (ACE2) in prefusion form. Transition to post fusion form leads to fusion of viral membrane and endosomal membrane in the cytoplasm [18].

E protein is the smallest protein of SARS-CoV2 that is involved in the production and maturation of viruses The $\mathrm{M}$ protein is responsible for maintaining the shape of the virus envelope and organizing the viral assembly.

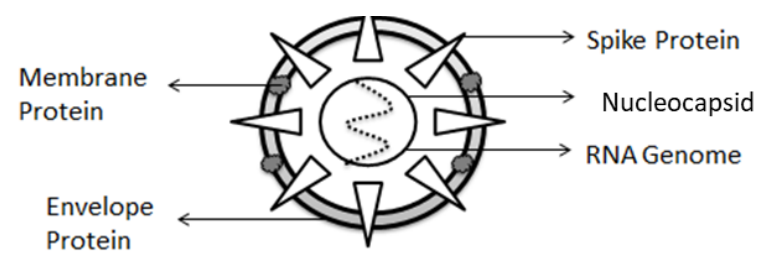

Figure 1. Structural features of SARS-CoV2

Table 1. SARS-CoV2 structural proteins

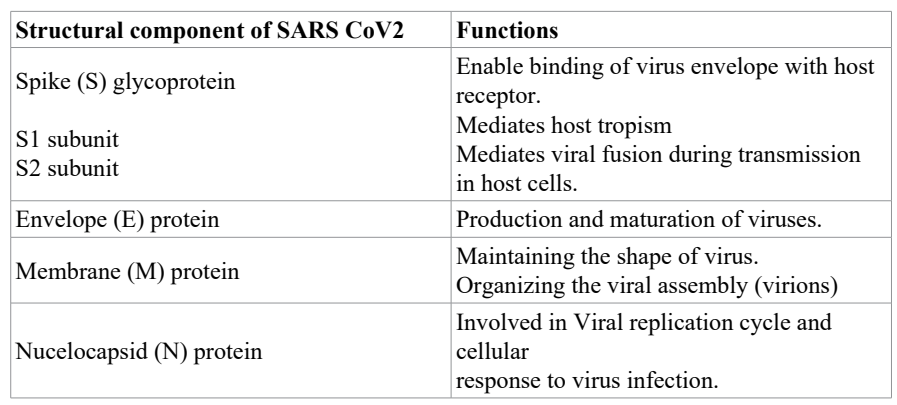

The $\mathrm{N}$ protein is highly phosphorylated found in association with the RNA genome and it is localized in the host endoplasmic reticulumGolgi region after infection. The $\mathrm{N}$ protein is involved in the viral replication cycle and in the cellular response mechanisms of host cells to viral infections $[19,20]$. The predicted structure and life cycle of SARSCOV is shown in Figure 1 and Figure 2 respectively.

\section{Covid 19-Nanotechnology interface}

The COVID-19 outbreak has fueled a global demand for the following: i) effective anti SARS CoV2 therapy ii) specific vaccine candidate iii) sensitive and reproducible diagnostic tool Currently, only few drugs like baricitinib and remdesivir have been approved by FDA. On the other hand, with only PCR assays and CT scanning occupying the forefront, the diagnostic tools are also meagre for early, specific and sensitive detection of COVID-19. At this stage, it's worthwhile to consider the superiority and advancements in nanotechnology for SARS-CoV2-management [12,21]. Singh, et al. have reviewed the application of nanotechnology for the targeted treatment of common viral infections [22]. One step ahead, Chan, et al. (2020), has enlisted a number of promising nanotechnology concepts and insisted that they can be a frontline to fight against COVID-19 in terms of nanotheranostics and management tools [11]. Nanomedicine opens new therapeutic avenues for attacking viral diseases and for improving treatment success rates which is equally applicable to SARS CoV2 also. Nanodelivery systems for antivirals mainly consist of nanoparticulate systems (including nanoparticles, nanocapsules, vesicles, dendrimers, micelles and inorganic nanomaterials), which have been designed to deliver small molecular weight drugs. Combining divergent classes of antiviral drugs, and nanoparticles surface will shape the future of long-acting anti SARS-CoV2 therapy [23]. In this context, targeting ligands for molecular recognition of viral nucleotides or protein sequences and imaging ligands can be functionalized on nanoparticles (so-called multifucntionalised nanoparticles) for successful targeting and imaging respectively. Multifunctional nanoparticulate antivirals systems show altered release kinetics, enhanced bioavailability, targeted therapeutic effects, meagre drug side effects, ability to overcome biological barriers and reduced treatment costs [24]. Diagnostic and surveillance technologies on the horizon for SARS-CoV-2 and their performance characteristics were reviewed addressing the scientists and researchers to advance their technologies beyond conception [25]. Present scenario which needs very imperative research attention to develop an effective drug and vaccine candidates to address the SARS$\mathrm{CoV}-2$ pandemic was appropriately pointed out by Sivasankaranpillai, et al. who subsequently reviewed the promising role and challenges of nanotechnology in combating COVID-19. Many challenges must be addressed prior to translation of advantages of nanotechnology into safe and effective anti-SARS-CoV2 formulations for clinical use [26]. Previous publications have evidenced the underuse of nanotechnologycoronavirus interface along with an inadequate number of publications and patents on coronavirus-nanotechnology interface $[12,13]$.

With the knowledge of nanotechnology-virology interface, it is possible to envision how nanotechnology can bridge the gap between the key stages of SARS CoV2 life cycle and the four factors of COVID-19 management viz, therapeutic, diagnostic, preventive and protective.

First, the therapeutic targets of SARS CoV2 are viral surface proteins and host cell receptor proteins involved in viral attachment, the acidic environment involved in the release of virus form endosome into the host cytoplasm, the enzymes of viral genome expression, the canonical RNA genome, the sub genomic RNAs, the vital enzymes and pathways involved in packaging and budding of new viruses from the host cells 


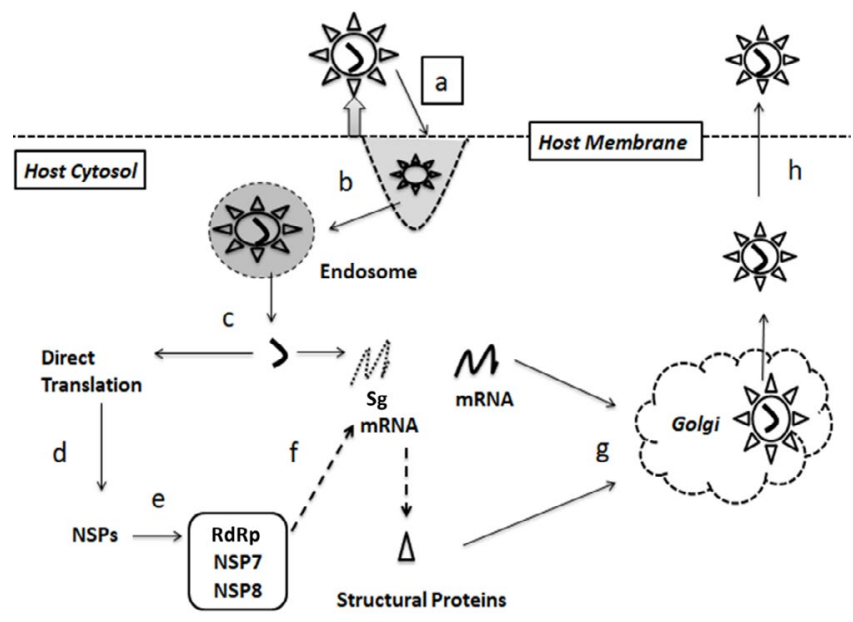

Figure 2. Life cycle of SARS-CoV2; a: Entry of SARS CoV2 into the host cell; b: endosome formation; c \& d: Direct translation and formation of non-structural proteins (NSPs); E \& f: Formation of Sg (sub genomic mRNA); g: Assembly of structural proteins and mRNA into new virions within the Golgi; h: Budding and gemmation of new virions out of host cell

[27]. Previous reports on therapeutic efficacy of nanomaterials against coronaviruses and enveloped positive sense RNA viruses, can by concept be used to propose promising nanotechnology-based therapeutic target for SARS CoV2. Novel drug repurposing and targeted delivery can undoubtedly be achieved using unique properties of nanomaterial such as possibility for surface engineering, sustained and controlled release of the cargo, deeper penetration in the target due to their size [28]. Silver nanoparticles are antiviral against HIV, hepatitis viruses and influenza viruses [29]. The Mechanism of antiviral effect of silver nanoparticles include inhibition of viral attachment and penetration into host cell, inhibition of viral gene expression and protein synthesis, prevention of intracellular virion assembly and release from host cells [30]. Graphene oxide nanosheets are reported to be inhibit porcine epidemic diarrhoea virus (PEDV) which also a coronavirus. It is known that SARS CoV2 depends on acidification of endosomes to gain access into host cell cytoplasm. Poly(ethylene glycol)-block-poly(lactide-coglycolide) nanoparticles were used for targeted delivery of diphyllin, which effectively act as an ATPase blocker and prevent the endosomal acidification-dependent cytoplasmic entry of feline coronavirus [31].

The preventive factors include vaccines of antigenic sequences of proteins, or peptide sequences, fusion proteins and mRNA of SARS $\mathrm{CoV} 2$ which can elicit safe immune response and also counteract inflammation and cytokine storm in the host cell [28]. Nanoparticles are good adjuvants for viral vaccines as they can elicit several fold higher quantities of antibodies when compared to conventional adjuvants. Although there is still no clinically approved vaccines for SARS CoV2, nanotechnoogy-based vaccines developed for coronaviruses may delineate the promising nanovaccines for COVID-19 [32]. In this regard, a coronavirus spike protein nanoparticle vaccine reported by Coleman et al. for SARS CoV and MERS CoV needs attention. S trimmers of the spike protein were isolated and purified to form higher ordered protein-protein micellular nanoparticles (the $\mathrm{S}$ nanoparticle vaccine). $S$ nanoparticle vaccine is capable of inducing immunity which gets boosted up in the presence of saponin based adjuvant leading to high antibody tire [33]. Chitosan nanoparticles are another choice for vaccination against coronaviruses. High density of positively charged amino groups on the chitosan is capable of forming favourable electrostatic attraction with the negative charges of epithelial cell membranes and mediate the targeted delivery of the genetic load It is possible to develop immunization against SARS $\mathrm{CoV}$ N-protein using biotinylated chitosan nanoparticles [34]. Gold nanoparticles conjugated to $S$ protein antigen enhances stronger antibody titers, and the splenic T-cell responses evidenced in an avian model of coronavirus infection [35]. As S protein and $\mathrm{N}$ protein are significant antigenic determinants in SARS CoV2, nanoparticles may be of relevant choice for vaccination against COVID-19.

The diagnostic factors encompass antigenic determinants, virulent proteins, the genome sequence of the native RNA or the sgmRNA and the antibodies raised against the antigens. All these factors can be used as targets to be captured by the diagnosis method. Nanoparticles-based detection method has been reported to provide signal amplification, high specificity and improved sensitivity in the detection of coronaviruses. Nanoparticles with tuneable optical properties such as metal nanoparticles and quantum dots, graphene oxide and iron oxide nanoparticles are reported sensing elements in the detection of various antigens of coronaviruses such as SARS CoV and MERS CoV. Graphene oxide may be considered as a primary material in diagnosis. Owing to its single layer of carbon atoms, graphene has an extraordinarily high surface to mass ratio which can result in modulation of its electrical properties upon single molecule binding. In addition, the surface oxygen of graphene oxide are sites for functionalization with proteins, enzymes, and nucleic acids. Thus, functionalized graphene oxide sheets can be used for meticulous single-molecule detection making it a perfect sensor! In fact, GO have potential to sense SARS CoV2 proteins and DNA targets [36,37]. Gold nanoparticles are used in sensing E protein and $\mathrm{N}$ protein antigens of MERS CoV and SARS CoV $[38,39]$. Semiconductor quantum dots-conjugated to RNA aptamer can specifically hybridize on the immobilized SARS-CoV N protein on the surface of a glass chip. This type of sensor had a detection limit of $1 \mathrm{pg}$ $/ \mathrm{ml}$ [40]. Zirconium quantum dots were also useful in the detection of coronavirus [41]. Silver nanoparticles were useful in the colorimetric probing of MERS CoV oligonucleotide target. Silver nanoparticles cationic pyrrolidinyl peptide nucleic acid were able to form complexes with anionic backbone of target oligonucleotide to produce a colour change [42]. A PCR assay utilizing superparamagnetic nanoparticles surface-engineered with silica were reported to detect SARS-CoV genome sequences [43].

Based on the role of nanoparticles in different aspects of virology, we could infer that understanding the interface between coronavirus and nanotechnology will direct the scientists and researchers towards a new era for the impeccable design and repurposing of antiviral drugs, vaccines and effective diagnostic tools for COVID-19. Entering the era of Nanotechnology-SARS CoV2 interface will not only be critical in counteracting COVID-19 but also be vital in the management of future pandemics. Hence, in the subsequent sections we reviewed the potential drugs, vaccines, diagnostic and management strategies for SARS-CoV2 pandemic with a special emphasis on the existing and promising role of nanotechnology. This interfacial approach will serve the purpose of future references and lead to rational design of nanotheranostic tools, vaccine candidates and value added non-therapeutic protective aids.

\section{Diagnosis of SARS-COV2: Current status and promising tools}

\section{Predictive Diagnosis}

2020 pandemic scenario of COVID-19, in spite of limited testing capacity available early detection is crucial especially for workers of 
health care settings and even for other workers. Hence, symptom-based screening may be used as predictive diagnostics. An array of simple tests, history of symptoms, and keen observations of image dataset would guideline predictive diagnosis enabling the clinicians, financial experts and health care workers to obtain forewarns on potential events that may happen and to decide on how to proceed further.

Symptom and temperature are valuable predictive diagnostic tools for SARS-CoV-2 infection status and surveillance. It was reported that, anosmia/ageusia, fever, and myalgia were the strongest independent predictors of positive assays. The absence of symptoms or symptoms limited to nasal congestion/sore throat were predictors with negative assays. It is suggested that predictive diagnosis may be generalized to other working populations during the pandemic [44].

Cohen et al. have suggested that chest X-rays (CXRs) as a rapid, non-invasive, relatively inexpensive tool and a good public resource to predict the disease status. Thereafter, the first public COVID-19 image data set was reported which encompasses several frontal and temporal view X-rays which is essential for getting COVID-19 diagnostic and prognostic data [45].

Biocompatible nano constructs when taken up by cells can scatter incident X-rays and produce enhanced signal in X-ray scatter images. Gold nanoparticles have high X-ray absorption coefficient than the typical iodine contrast agent and helps in in vivo imaging with high sensitivity over that of typical absorption based x-ray imaging [46]. Rand, et al. have fabricated a novel apoferritin-based "nanobubble" filled with perfuoroporpane gas which when injected in vivo results in high contrast X ray imaging [47] which may be useful to predict SARS CoV2 infected lungs.

\section{Pooled Testing}

The fastest and inexpensive mode of screening and predicting the COVID-19 risk is the Group testing, also called as the pooled testing [48]. Pooled testing has already been used for screening infections caused by Hepatitis B and C, Zika virus and HIV [49]. The Food and Drug Administration issued an emergency-use authorization to Quest Diagnostics that would allow the lab testing company to pool samples from up to four patients to test for the COVID-19. Tinashe, et al. have analyzed the validity of pooled resting in screening COVID 19 [50]. In pooled testing technique, individual samples from a group are mixed or pooled into one and tested. Negative results indicate that the group is devoid of infection while positive test claims for individual testing after subgrouping. For example, consider a group of 20 individual with one positive. Then the pooling test can proceed as shown in Figure 3. As per the illustration, it is understood that all the 20 persons get screened with just 10 number of tests instead of 20.

\section{RT-PCR based assays are promising front line diagnostic tools for COVID-19}

The genomic sequence of SARS-CoV-2 was disclosed in the public databases after the outbreak of COVID-119 in Wuhan [51]. Specific gene sequences of this genome were used to design primer and probes. The first open reading frames (ORF $1 \mathrm{a}$ and $1 \mathrm{~b}$ ), RdRp, genes encoding E protein, $\mathrm{N}$ proteins and S proteins are key targets for COVID-19 diagnosis. Various kits are being developed to detect one or more of these target genes. The primers used in RT PCR are shown in Table 2. All the diagnosis can be done using the respiratory tract test specimens such as i) nasal swabs, pharyngeal swabs, sputum or broncho alveolar lavage fluid (BALF) in the presence of viral RNA extracted from SARS$\mathrm{CoV}$ as positive control [52].

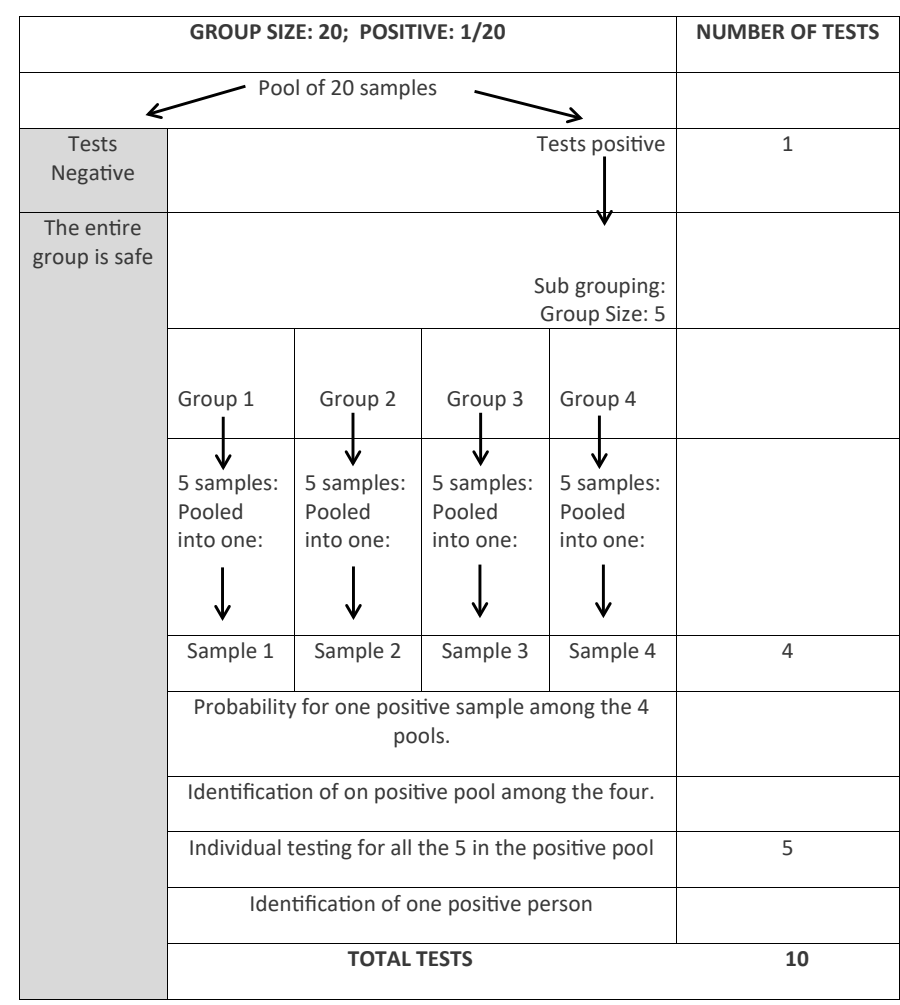

Figure 3. Pooling test protocol for SARS CoV2 detection. (The example shows that 20 patients can be screened with just 10 tests)

Table 2. Primer sets used in RT-PCR based diagnosis of COVID-19

\begin{tabular}{|l|l|}
\hline $\begin{array}{l}\text { Primer sets: } \\
\text { The genes (from 5, end) }\end{array}$ & Description \\
\hline ORF1a & Function in viral RNA replication \\
\hline ORF1b & Function in viral RNA replication and mRNA transcription \\
\hline Envelope (E) protein & $\begin{array}{l}\text { Involved in assembly, budding, envelope formation, and } \\
\text { pathogenesis }\end{array}$ \\
\hline RdRp/Helicase gene & Functions as an ATP-binding helicase in RNA replication \\
\hline Nucleocapsid (N) protein & Role during virion assembly \\
\hline Nsp2 gene & $\begin{array}{l}\text { Transcriptional regulator essential for Nod-factor-induced } \\
\text { gene expression }\end{array}$ \\
\hline
\end{tabular}

Nanoparticles were incorporated into conventional coronaviraldetecting PCR assays to give better performances such as less reaction time, enhanced signal amplification, high specificity and improved detection sensitivity towards coronavirus family members. These nano PCR strategies were reviewed here which will be promising in the development of marketable SARS COV-2 detection kits. Silica-coated superparamagnetic nanoparticles and gold nanoparticles were used in PCR assays for specific and sensitive detection of the genetic sequences SARS-CoV and PEDV (porcine epidemic diarrhoea virus) respectively [43,53]. Members of coronavirus family such as transmissible gastroenteritis virus (TGEV) and PEDV were detected with relatively high magnified PCR signals by using viral-specific oligonucleotidescapped gold nanoparticles [54].

\section{Nanoparticles-based Colorimetric assay}

Colorimetric assays are a typical tool to simply identify the target molecules visually by measuring the absorbance of indicators like nanosized metallic particle and dye molecules at specific wavelength. Gold nanospheres of approximately $20 \mathrm{~nm}$ prepared by citratereduction method was used in colorimetric assay of MERS-CoV target 
genome, to give naked-eye visualization at UV-visible wavelength. First, thiolated probes were designed at either the $5^{\prime}$ end or $3^{\prime}$ end to organize complementary base pairs with upstream of the E protein gene (upE) and ORFla on MERS-CoV. Thiolated probes were allowed to hybridize with target gene via disulphide bonds to form double stranded hybrid. The hybrids form extended self-assembled complex which can protect bare gold nanoparticles for stability against saltinduced aggregation and transition property. This is because, the sulfur-group at ends of double-stranded hybrid mediate covalent bond with gold surface. The limit of detection (LOD) of this colorimetric platform was $1 \mathrm{pmol} / \mu \mathrm{L}$ which corresponds to almost 26 PCR cycles compared to conventional PCR reactions that require more than about 34 cycles to detect MERSCoV. This concept of a gold nanoparticlesbased colorimetric assay may have potential for diagnosis of other infectious diseases including SARS-CoV2 [38].

The poly-dimethylsiloxane (PDMSO) microfluidic channels were fabricated on the gold surface. Gold binding polypeptide (GBP) was used as a fusion partner for nanopatterning of proteins on gold surface. This platform was used for high-throughput analysis of antigenantibody and DNA-DNA interaction studies to reveal specific biomarkers. SARS-CoV E protein and green fluorescent protein when immobilized on gold nanoparticles may produce significant changes in the absorbance and colour upon the interaction with a complimentary antibody, thus allowing for the quantitative detection of SARS-CoV [55]. This fusion partner technique may certainly be an emerging and promising area of research to detect SARS CoV2 E protein.

\section{Optical sensor}

Chiral zirconium quantum dots and magneto-plasmonic nanoparticles were separately functionalized with anti-bronchitis coronavirus antibody. The hybrids can be magnetically separated for the subsequent detection of fluorescent signals [41]. Recently, Qiu, et al. have developed a gold nanoparticles-based biosensor for accurate diagnosis of COVID-19 disease. Sensing was done when plasmonic photothermal (PPT) effect and LSPR are combined as transduction principles. The LSPR substrate of gold nanoparticles is illuminated to generate local heat and detection of binding nucleic acid binding events. LSPR response to thermoplasmonic effect and towards detection of nucleic acid sequences at low concentrations were documented. DNA receptors are used to detect selected sequences from SARS-CoV2. This LSPR biosensor detects a concentration of $0.22 \mathrm{pM}$ exhibiting high sensitive towards the selected SARS-CoV-2 sequences in a multigene mixture [56].

\section{Immunochromatographic assay (ICA) using nanotechnology}

PEDV is also a coronavirus with positive sense RNA like SARS CoV2. An immunochromatographic assay (ICA) using immobilized gold nanoparticles $(40 \mathrm{~nm})$ was successful in detecting PEDV spike protein antigens, which could also be modified for detecting SARS$\mathrm{CoV} 2$ in future. The ICA system contains a strip designed serially with optimized sample pad, conjugation pad, nitrocellulose membrane, and absorption pad. The detection antibody which is complementary to the epitope of spike protein was immobilized on gold nanoparticles embedded in conjugation pad (at one end of the strip). The capturing antibody was coated to nitrocellulose membrane (at the other end of the strip). When a sample with spike protein (antigen) is placed on the sample pad, it will bind to the antibody bound gold nanoparticle and gets sandwiched by the capture antibody to form a red signal. This is an on-site detection method with a limit of detection as $0.47 \mu \mathrm{g} / \mathrm{mL}$ [57].

\section{Nano immunosensor}

An electrochemical biosensor with array of nano-structured carbon electrodes was developed for $\mathrm{HCoV}$ (human corona virus) and MESRS $\mathrm{CoV}$ detection. The biosensor was based on indirect competition between free virus in the sample and immobilized MERS-CoV protein for a fixed concentration of antibody added to the sample. The change in the peak current of the square wave voltammetry (SWV) signal in the presence of different concentrations of the MERS-CoV antigen were recorded. This immunosensor showed low detection limit, high degree of selectivity against other non-specific protein [58].

Recently, Seo, et al. have developed a nano immunosensor for the rapid Detection of COVID-19 Causative Virus (SARS-CoV-2) in human nasopharyngeal Swab specimens Using graphene-based FieldEffect Transistor (FET). The graphene sheets (surface $\sim 0.961 \mathrm{~nm}$ ) of FET was coated with antibodies raised against spike protein of SARSCoV- through 1-pyrenebutyric acid N-hydroxysuccinimide ester (PBASE), an efficient interface coupling agent used as a probe linker. The antibody sensor was successful in sensing the COVID-19 in antigen medium, cultured virus, and nasopharyngeal swab specimens from COVID-19 patients. The limit of detection was found to be $1 \mathrm{fg} / \mathrm{mL}$ in phosphate-buffered saline and $100 \mathrm{fg} / \mathrm{mL}$ in clinical transport medium, $1.6 \times 101 \mathrm{pfu} / \mathrm{mL}$ in SARS-CoV-2 in culture medium and $2.42 \times 102$ copies $/ \mathrm{mL}$ in clinical samples. Interestingly, the device exhibited no measurable cross-reactivity with MERS-CoV antigen. This emphasise the specificity of the device [59].

\section{RNA aptamer-based sensing of SARS CoV N-protein}

Roh and Jo have used RNA aptamer-quantum dot hybrid to recognize the SARS-CoV N-protein with a detection limit of $0.1 \mathrm{pg}$ $\mathrm{mL}^{-1}$ on a designed chip. They clearly suggested that this technique has potential applications in multiple diseases detection [40]. Hence, if the aptamer is designed to bind to SARS-CoV2 nucleocapsid protein it would emerge as a covid-19 sensor.

\section{Point-of-care approach using gold nanoparticles}

Point-of-care tests refers to the diagnosis of infected patients without sending samples to centralized facilities. Lateral flow antigen detection using gold nanoparticles for testing SARS-CoV-2 was reported to be a successful point-of-care approach [60]. In this method, a double-streaked membrane strip bearing antibodyconjugated gold nanoparticle in one streak and capture antibodies in the other streak was used. When the patient's sample was deposited on the membrane it experiences capillary flow. The antigens in the sample bind to the gold nanoparticle-antibody conjugates (in the first streak) and gets immobilized by the capture antibodies in the second streak. Individual gold nanoparticles were red in colour, but a solution containing clustered gold nanoparticles was blue due to the coupling of the plasmon band.

\section{Biobarcode assay}

The bio-barcode is an ultrasensitive nanotechnology-based diagnostic tool used for the detection of various protein and nucleic acid targets [61]. Quantum dot based biobarcode assay for sensitive detection of multiple regions of viral genome of Hepatitis B Virus (HBV) was validated earlier [62]. Based on previous review, Udugamma et al. suggested Biobarcode assay involving nanoparticles as one of the emerging technologies with clinical feasibility that can be adapted for detecting SARS-CoV-2 also [25,63]. 


\section{Potential therapeutic strategies}

Researchers have tested some therapeutic agents against SARS $\mathrm{CoV}$ and SARS CoV2 in vitro and in vivo models. Convalescent plasma therapy, antibodies nanobodies, anti-malarial drug Chloroquine, SiRNA, antiviral molecules such as inhibitors of viral attachment replication enzyme inhibitors, nuclear import pathway inhibitors, transcription enzyme inhibitors, nucleoside analogues and antiinflammatory drugs. could be therapeutic options for SARS-CoV-2.

\section{Convalescent plasma therapy, antibodies and nanobodies}

Convalescent plasma (CP) transfusion lines up as first-choice of treatment for covid-19 [64]. Monoclonal antibodies directed to the $\mathrm{S}$ glycoprotein of SARS-CoV inhibit the interaction of the virus with the host receptor ACE2 thereby interfering with the infection process [4]. CR3022 is a SARS-CoV2-specific recombinant monoclonal antibody raised against $\mathrm{S} 1$ glycoprotein which binds to the RBD domain [65]. Wang, et al. 2020 were the first to report a (human) monoclonal antibody 47D11 that neutralizes SARS-CoV-2 [66]. The antibody binds a conserved epitope on the spike RBD explaining its ability to crossneutralize SARS-CoV and SARS-CoV-2, using a mechanism that is independent of receptor-binding inhibition. The original antibody, human IgG1 was reported to have affinity for nCoV2019. This antibody may be a potential therapeutic candidate by itself or in combination with other neutralizing antibodies to combat SARS-CoV2 infection [65]. Much earlier studies by et al. have highlighted the possible favorable effects of nano immunoliposomes in the targeted delivery of viral antibodies using indinavir (anti-HIV antibody) as an example [67]. Nanobodies (Nbs) are recombinant single domain antibodies (approximately $20 \mathrm{~nm}$ ) isolated from the variable $\mathrm{VHH}$ domains of heavy chain-only antibodies (HCAbs) occurring in camelids (e.g., dromedaries, llamas, alpacas, etc.) [68,69]. Four anti-viral nanobodies (raised against E2 glycoprotein of hepatitis $\mathrm{C}$ virus) have been isolated and one nanobody was proved to be a potential candidates for immunetherapeutic administration in chronic hepatitis C [70].

\section{Chloroquine and Nanomedicine}

The 70 year old antimalarial drug Chloroquine follows an antireplicative strategy to prevent replication in canine corona virus [71]. Later studies revealed that chloroquine inhibited SARS-CoV replication with an EC50 value of $8.8 \pm 1.2 \mu \mathrm{M}$, within the range of blood concentrations achievable during antimalarial treatment [72].

Chloroquine has been used in the field of nanomedicine to investigate interaction of cells with nanoparticles of spherical shapes [73]. SARS-CoV2 are also spherical and falls within the nano size range 8 and are almost similar to the experimentally studied synthetic nanoparticles [51,73]. Hence, nanomedicine studies may provide clues on chloroquine-induced alterations of SARS-CoV-2 cellular uptake also [74]. Phosphatidylinositol binding clathrin assembly protein (PICALM)- dependent clathrin mediated endocytosis is the chief pathway of nanoaprticles internalization [75]. Diminution of PICALM has earlier been reported to hinder clathrin-mediated endocytosis [76]. Hence, it is possible that one of the mechanisms responsible for chloroquine-mediated effects against nanoparticles or SARS-CoV-2 is a general decrease in the clathrin-mediated endocytosis due to PICALM suppression. Secondly, Chloroquine is a weak base capable of increasing lysosome $\mathrm{pH}$. Lysosomes however need an acidic $\mathrm{pH}$ for autophagy pathway. Hence, chloroquine prevents recycling of lysosomal cargo (such as SARS CoV2 and nanoparticles) [74].

\section{SiRNA strategy}

Small interfering RNAs (siRNAs) targeting the genomic RNAs and/or sgmRNAs have been claimed as a treatment regimen for SARS in humans. In SARSCOV-infected Macaca mulatta model, intranasal administration of chemically synthesized siRNA duplexes ameliorated fever, viral titre and acute diffuse alveoli damage without toxic effects. This study suggest that SiRNA knocks down the synthesis of protein needed for viral replication and virulence [51]. PEGylated cationic liposomes encapsulating siRNA (so called cationic lipoplexes) were reported to be efficient in target gene knock down and the effect depends on the types of lipids used [77]. Hence, liposomal delivery of SiRNA would be mediate a better gene therapy strategy for SARS CoV2 infection.

\section{Ivermectin}

Importing $(\mathrm{IMP} \alpha / \beta 1)$ is involved in nucleocytoplasmic shuttling of SARS-CoV nucleoprotein. SARS-CoV accessory protein ORF6 has been shown to antagonize the antiviral activity of the STAT1 transcription factor by sequestering IMP $\alpha / \beta 1$ on the rough ER/Golgi membrane [78]. Taken together, ivermectin's nuclear transport inhibitory activity may be effective against SARS-CoV-2. Subsequently, Caly, et al. reported that Ivermectin has antiviral action [79] against the SARSCoV-2 clinical isolate in vitro, with a single dose able to control viral replication within $24-48 \mathrm{~h}$ in our system. Caly, et al. hypothesise that this antiviral action is likely through inhibiting IMP $\alpha / \beta 1$-mediated nuclear import of viral proteins as shown for other RNA viruses. Lipid nanocarriers were reported to be ideal for the encapsulation and rapid delivery of ivermectin with enhanced activity at the target site when compared to free ivermectin [80].

\section{CLpro inhibitors}

3CLpro is the main protease involved in viral genome processing and hence it's a prominent therapeutic target. Many studies were focused to identify the 3CLpro inhibitors for potential therapy of COVID-19. In silico studies by Gyebi, et al. 2020, [81] revealed that natural alkaloids and terpenoids are inhibitors of 3CLpro with highly conserved inhibitory pattern to both SARS-COV-2 and SARS-COV. The docking scores were compared with 3CLpro reference inhibitors (Lopinavir and Ritonavir). A pilot study on MERS CoV suggest that polyanionic dendrimers enhance the intrinsic activity and delivery of antivirals and that these dendrimers can be a base for further modifications and inclusions in antiviral therapy [82]. Khan, et al. have carried out the systematic drug repurposing approach to identify 3CLpro inhibitors as antiviral drugs and to unravel the inhibitory mechanism through extensive in silico approaches and binding free energy $(\Delta G)$ of the drugs. Polymeric, metallic and lipid nanoparticles are ideal nanosystems for 3CLpro inhibitor cargos like paritaprevir [83]. Gold nanoparticles, were reported carriers for sustained delivery of raltegravir to fight against virus [84]. Polymethyl Methacrylate $[\mathrm{PMM}]$ nanoparticles, $\epsilon$-Caprolactone-Based nanoparticles (ECL) functionalized with specific targeting ligand are reported to deliver raltegravir for antiviral applications [85]. Pillaiyar, et al. have intensively reviewed and discussed about non-covalent type peptidomimetics inhibitors of 3Cpro. The inhibitors carrying specific chemical group /warhead (Michael acceptors, aldehydes, epoxy ketones, halomethyl ketones) for non-covalent binding to close proximity sites of catalytic residues dampens the 3CLpro. Nanodelivery system functionalized with monoclonal antibodies, receptor-specific peptides or proteins, DNA/RNA aptamers, and small molecules such as folates, vitamins or carbohydrates can enable site-specific delivery of small molecules 
which may be considered for the delivery of small inhibitor molecules. Polymeric polyethylene glycol polymethyl methacrylate nanoparticles, gold nanoparticles and iron nanoparticles were used for the delivery of small molecule $[86,87]$.

\section{The PLpro inhibitors}

In addition to its main role in processing of viral polyprotein, PLpro stripes ubiquitin and ISG15 from the host cell proteins and enables the virus evade the host innate immune response. Using SARS-CoV2 homology model, Arya, et al. have virtually screened the inhibition of S3/S4 pockets of the PLpro catalytic domain by FDA approved using docking studies. Chloroquine and formoterol, was found to bind the target enzyme with significant affinity suggesting their potential as promising inhibitors of SARS-CoV2 PLpro [88]. Choromphenicol has already been discussed in earlier section. For formoterol, carbohydrate polymer-based nanoparticulate systems were reported to be ideal for pulmonary delivery and high efficacy [89-91]. Polyvinyl alcohol (PVA)coated magnetite nanoparticles were reported as ideal nanocarrier for the sustained release and targeted delivery of 6-MP with lower therapeutic dose and lower side effects [92]. Moreover, CdSe/ZnS coreshell quantum dots offer triple advantages of being an efficient carrier for 6-TG and a tracking tool owing to its fluorescence, a suppressor of adverse drug properties resulting from the presence of thione group in the 6-TG structure [93]. Disulphide-based polyethyeneglycol (PEG)conjugated nanogels of $60 \mathrm{~nm}$ were used to entrap 6-Methylguanine with high pay load and stimuli-responsive release property [94].

\section{2'OMTase inhibitors}

2'-OMTase is a potential drug target for identification and screening of FDA approved drugs for repurposing. Docking analysis displayed that the active site of 2'OMTase accommodates an array of drugs which includes alkaloids, antivirals, cardiac glycosides, anticancer, steroids and other drugs. The results suggested that these drugs may be used as potential inhibitors for 2'OMTase for combating the SARS-CoV-2 infection [95]. Dolutegravir $(\Delta \mathrm{G}=-9.4 \mathrm{kcal} / \mathrm{mol})$ and Bictegravir $(\Delta G=-8.4 \mathrm{kcal} / \mathrm{mol})$ were reported as excellent lead candidates to inhibit 2'-OMTase which may have promising role against 2019-nCoV [96]. Sillman, et al. reported a first step towards the formation of polaxomer nanoformuated long-acting doluteglavir for human use by with antiretroviral potency [97]. Poly (lactic-co-glycolic acid)-loaded bictegravir nanoparticles formulated using an oil-inwater emulsion protocol resulted in controlled release with a lower inhibitory concentration (EC50) against HIV infection in a proof of concept study [98].

\section{Ntpase/helicase inhibitors}

Aryl diketoacids have been identified as the first SARS-CoV NTPase/helicase inhibitors reported in anti-MERS and anti-SARS chemical therapies [99]. Recently, Bismuth salts such as bismuth potassium citrate (BPC), ranitidine bismuth citrate (RBC) at a dose of $10 \mu \mathrm{mol} / \mathrm{L}$ inhibited the ATPase activity and almost abolished helicase activity of SARS-CoV-2 nsp13. Bismuth salt nanoparticles synthesized by water-in-oil (w/o) microemulsion-assisted hydrothermal method has already been reported to exert comparable anti-infective activity as compared to the clinically used drug, colloidal bismuth subcitrate (CBS), which offers a promise for development of new nanomedicines [100]. Coronaviruses rely upon endosomal acidification for cytoplasmic entry (discussed under life cycle). Polymeric nanoparticles consisting of poly(ethylene glycol)-block-poly(lactide-co-glycolide) (PEG-PLGA) encapsulated with diphyllin (a novel vacuolar ATPase blocker) is capable of inhibiting the endosomal acidification and downstream viral replication [31]. Further studies on arydiketoacids, BPC and RBC will lead to a development of replication-targeting viral therapeutics for COVID-19 [101]. In order to get the most desirable therapeutic effect and to minimize the negative side effects, it is also very important to ensure that the helicase inhibitors are delivered specifically to their sites of action within the cells. Nuclear targeted delivery of these small molecule inhibitors might be achieved using nanoparticles liganded with nuclear localization signal [102]. Similarly, clinically approved nanoparticles should be considered to deliver the helicase inhibitors selectively to the target tumor sites at sufficient concentration to attain therapeutic efficacy [103].

\section{RdRp inhibitors}

The active site of RdRP seems to be a principal target for the antiviral drugs Remdesivir, Galidesivir, Ribavirin Sofosbuvir, and aurin tricarboxylic acid (ATA) [4]. ATA can be nanoformulated with polymers for better efficacy. These reports insist that, like other nano-functionalized MAPK inhibitor, ATA can also be delivered using nanocarriers thus providing a novel approach for SARS-CoV2 targeting [104,105]. However, RdRp are hotspots of mutation in SARS $\mathrm{CoV}-2$ and naturally occurring mutations in critical residues can lead to drug resistance phenomena, with a significant loss in the binding affinity for antiviral molecules. This is an important factor to be addressed during drug design [106].

Our review on SAR-CoV2 vital enzymes (3CLPro, PLpro, 2'OMTase, NTPAse/helicase, RdRp) divulges scarcity of publications on nanotechnology-based enzyme targeting. Research in this area at in vivo and clinical level will certainly produce effective anti SARS-CoV2 strategy.

\section{TMPRSS2 inhibitors}

TMPRSS2 is a host enzyme with protease activity which primes the $\mathrm{S}$ protein to facilitate its binding to ACE2. In alveolar epithelial cells, ACE2 and TMPRSS2 genes are co-expressed with genes involved in innate immunity, highlighting the cells' potential role in initial viral infection, spread and clearance [107]. According to studies, SARSCoV-2 depends on TMPRSS2 to facilitate entry into the host cell and inhibitors of TMPRSS2 serine protease will be another feasible therapeutic approach for SARS-CoV2 infection 12. Camostat mesylate inhibits TMPRSS2 to prevent viral entry into host cell $[108,109]$. Poly(lactic-co-glycolic acid) (PLGA) nanospheres (prepared by the emulsion solvent diffusion methods in water or in oil emulsion solvent evaporation method) were efficient carriers of camostat mesilate with $85 \%$ release efficacy [110]. Hence, polymeric nanoparticle-mediated targeted delivery of inhibitors of TMPRSS2 serine protease may emerge as a novel treatment approach Targeted pulmonary delivery avoids first-pass hepatic metabolism thus reducing dose requirement [111]. Liposomes, polymeric NPs, solid lipid NPs, and dendrimers are reported nanoplatforms for pulmonary drug delivery [112]. A Russian patent has disclosed a protocol for the nanoencapsulation of arbidol in carrageenan [113]. Hence, targeted delivery of arbidol drug by nanoencapsulation would be of use in SARS-CoV2 treatment approach.

\section{Therapeutic approaches targeting inflammation and cytokine storm}

A recent study after SARS-CoV2 outbreak conducted by $\mathrm{Wu}$, et al. revealed lung damages and lesions during early and severe stages of covid-19 owing to both the pathogen replication and the 
host-generated inflammation associated with the recruitment of immune responses [114]. Hence, mitigation of inflammation would be a therapeutic approach. Wiley, et al. have designed a protein cage nanoparticle (PCN) capable of accelerating the viral clearance and decreasing the lung damage by induction of BBALT (inducible bronchus associated lymphoid tissue). This is a promising strategy for pulmonary immunoprophylaxis which could enhance primary immune responses to a spectrum of respiratory viruses [115]. Leukemia inhibitory factor (LIF) binds to the type II epithelial cells in the alveolar wall and promotes regenerative repair by viral clearance and by the prevention of the vascular leak and the alveolar tissue damage [116]. LIF, administrable by inhalation, intravenous or ventilator-assisted breathing is a rapidly available treatment resource for COVID-19 pandemics. It has the potential of naturally increasing resistance to severe COVID-19 disease [117]. PLGA nanoparticles-based targeted delivery of LIF was reported to be successful in the treatment of multiple sclerosis [118]. Similar strategies hold the potential for treating SARS infections with a greater selectivity and efficacy than the conventional therapies [12].

Recently, SARS-CoV2 infections have been reported to be characterized by hyperinflammatory state characterized by a fulminant cytokine storm (so called hypercytokinemia) before acute respiratory distress syndrome and death [119]. In this context, Dormont, et al. have designed a targeted multifunctional nanocarrier containing squalene (a natural lipid) adenosine an endogenous immunomodulator) and $\square$-tocopherol (an antioxidant). The antioxidant and the immunomodulator helped treating the inflammation. This type of therapeutic approach would be ideal for treating inflammation associated with SARS-Cov2 [120].

Nanoformulation of p38 MAPK inhibitors may enable controlled release and targeted delivery. Reported nanoformulations of the p38 MAPK inhibitors are GSK 678361A encapsulated in Poly(lactic-coglycolic acid) nanoparticles and PH797804 polymeric nanocrystals $[121,122]$. We imply that p38 inhibitors can be delivered using nanocarreirs for better anti ACOVID-19 action.

\section{Other Promising therapeutic approaches}

Viral matrix-2 (M2) protein forms a proton-selective ion channel called viroporin which mediates acidification of endosome and disrupts the viral nucleoproteins, matrix protein 1 and lipid bilayers thereby freeing the viral genome for entry into the host cell [19]. Salinomycin was reported to inhibit virus infection by inhibiting M2 proteinmediated viral entry [123]. Pindiprolu, et al. have reported a nanolipid carrier for the intra-pulmonary delivery of salinomycin which is a valid approach to prevent SARS-CoV-2 infection by improved absorption at the infection site. This nano-delivery system has additional advantages of non-invasive administration, avoidance of first-pass metabolism, lack of off-target effects [124]. Graphene oxide nanosheets, owing to their single layered sharp edges were reported to exhibit antiviral property against RNA and DNA viruses. Structural destruction prior to viral entry was the proposed mechanism of action. SARS-CoV2 being an RNA virus may also be targeted with GO and modified GO [125]. Silver nanoparticles have antiviral effects (HIV, hepatitis viruses and influenza viruses) and they inhibit the viral entry into the cell [29]. A composite of graphene oxide and silver nanoparticles were reported to be effective against feline coronavirus ( $\mathrm{FCoV}$ ) which is an enveloped RNA virus similar to SARS-CoV2. The mode of antiviral efficacy is probably by destruction of the outer covering of the virus. Studies on the interactions between GO and lipid membranes showed that negatively charged GO can absorb to positively charged lipid membranes and induce the rupture of lipid membrane [126]. In coronavirus model, bovine serum albumin (BSA)-coated tellurium nanostars were able to bind to heparan sulfate analogs (mediator of viral attachment and internalization) and inhibit the viral entry into the host cell. This study proved that the tellurium-based nanostars would be a therapeutic platform for SARS CoV2 [127].

\section{Pharmacogenomics, nutrigenomics and nutrigenetics in personalized medicine for COVID-19}

Personalized Medicine refers to the treatment based on the individual patient's specific characteristics, including age, gender, height/weight, diet, environment, nutritional habits and pharmacogenetic characteristics etc. Genetic factors can also alter the drug efficiency and toxicity in populations with COVID-19. Hence, Pharmacogenetics based personalized medical care based on expression levels of pharmacogenes has become essential. Wang, et al. have depicted the Variations profiles of pharmacogenes of drugs for COVID-19 therapy and the genetic profiles in pharmacogenes Indicate personalized Drug Therapy for COVID-19 Single cell RNA sequencing studies suggest the involvement of i) Pharmacogenes, including CYP3A4, $A B C B 1, S L C O 1 B 1, A L B, C Y P 3 A 5$, in the process of COVID-19 drugs ii) around 100 drug-drug-interactions iii) racial discrepancy of common nonsynonymous mutations in pharmacogenes including $V D R, I T P A, G 6 P D, C Y P 3 A 4$ and $A B C B 1$ which is related to the COVID-19 drugs including ribavirin, $\alpha$-interferon, chloroquine and lopinavir. These data insist for personalized medicine in which the drugs affected by interactions with other drugs should be replaced and the chloroquine should be preferred over other drugs to target ACE2 [128]. Nutrigenomic and nutrigenetic approaches can also enable personalized medicine by normalizing the metabolic activities such as oxidative stress and inflammation as inflammation and oxidative stress are characteristic feature of SARS CoV2 infection [129]. The implementation of pharmacogenetics and nutrigenomics based personalized medicine in COVID-19 may reduce the possible adverse reactions to drugs, and save the pharmaceutical costs of ineffective treatments, giving a better quality of life for the patient.

Nanotechnology and personalized medicine are rapidly converging in numerous current and future clinical applications. Nanotechnology based DNA sequencing and SNP analysis is advantageous in pharmacogenomics [130]. Marchant, et al. have reviewed the opportunities and challenges in applying nanotechnology to personalized medicine and also addressed the policy, legal and ethical issues related to the convergence of nanotechnology and personalized medicine. Contributions of nanotechnology for personalized medicine applications incudes the size that matches the scale of the molecular substrates of personalized medicine, high sensitivity of detection, high specificity of binding with target molecules, and specific properties at the nanoscale [131].

\section{Potential vaccine candidates for SARS-CoV2}

Vaccine is the fundamental value and the mortality reducing factor, which is very essential for the prevention of the serious COVID-19 outbreak and for the protection global heath. Currently, there is no approved vaccine against SARS-Cov-2. The potential candidates are basically protein vaccines, peptide vaccines, subunit vaccines, DNA vaccines or mRNA vaccines.

Development of all vaccines mainly depends on precise interaction mechanisms between the virus surface molecules and the host receptors. The most possible vaccine candidate is the spike protein of 
the SARS-CoV2 as the S1 subunit of the spike protein is reported to interact with the host receptor ACE2 to initiate the infection process [132]. The second possible option is the vaccine derived directly from the receptor-binding domain of the virus [133].

Few of the vaccines developed by lead pharmaceutical companies or organisations such as NVX-CoV2373 (Novavax), PiCoVacc (Sinovac), Ad5-nCoV (CanSino Biologics), AZD1222 (University of Oxford and AstraZeneca), INO-4800BNT162 (Inovio), (BioNTech and Pfizer), mRNA-1273( Moderna and NIAID) are reported to be under clinical trials [134]. Apart from direct studies on SARS CoV2 vaccine development, few studies on other members of coronavirus family such as SARS CoV and MERS CoV holds promise for being developed into a SARS CoV2 vaccines. Here are few examples. A single plasmid DNA vaccine encoding the $S$ protein obtained from the SARS-Cov-viral has already been shown to elicit SARS CoV specific antibodies, neutralising antibodies, CD4+ T-cell responses and CD8+ $\mathrm{T}$-cell responses. This vaccine is under phase I clinical trial. This could show a promising effect against COVID-19 [135]. Subunit vaccines hold the merit of safely inducing the immune system against MERS $\mathrm{CoV}$ without side effects as it bypasses the direct injection of infectious agent into the host cell. Subunit vaccines stimulate $\mathrm{T}$ cell response and generate high titre of antibodies in vivo. This is applicable for similar types of studies using SARS CoV2 [136].

\section{Antibody-dependent enhancement (ADE) and Higher mutation rate of RNA viruses are hurdles in vaccine development}

ACE is a phenomenon, in which vaccination-mediated antibodies turn as side effect by inducing viral infectivity through Fc receptor pathway [137]. This is an important hurdle in the development of viral vaccines. In fact, $\mathrm{ADE}$ was reported during vaccine development against Dengue and Zika viruses [138]. Further, ADE was demonstrated during vaccination against the beta coronavirus member SARSCov also $[139,140]$. Hence, indisputably, ADE is considered as a major factor during SARS-CoV-2 vaccine development also. ADE can to a certain extent be circumvented by generating vaccines pertaining to non-surface proteins. For example, N-protein is not a surface protein and DNA vaccine developed against $\mathrm{N}$ protein of SARS Cov2 may overcome $\mathrm{ADE}$ and do not induce viral entry during the course of vaccination. They can elicit N-protein specific cellular and humoral immune response [141]. RNA viruses like SARS Cov2 shows higher mutation rate when compared to DNA viruses leading to much diversity. This is more pronounced in the SARS CoV2 because the RBD of the spike protein coding region is the most variable region in the coronavirus genome. Thus, mutation rate should also be considered as serious criteria during vaccine development [5].

\section{Possibility of Nanoparticle vaccine technology for SARS CoV2}

Nanocarriers-based and nanoadjuvant-based vaccine delivery has been used for preventing infections [32,142]. As clinically available vaccine is lacking for coronavirus, nanotechnology-based vaccines or nanoparticles-based improvement in the existing vaccine if developed will certainly achieve a several-fold increase in immunostimulatory effect. In 2014, Coleman, et al. have described a novel method for creating full length spike nanoparticles (S-nanoparticles) of SARS$\mathrm{CoV}$ and MERS-CoV [32]. In 2017, Coleman, et al. have confirmed that mice vaccinated with MERS-CoV S-nanoparticles adjuvanated with Matrix-M1 resisted MERS-CoV replication in the lungs. The
MERS-CoV S + Matrix-M1 nanoparticle formulation is a prime candidate for further development for use in camels or humans [143]. Nanovesicles displaying S protein, M protein and E protein of MERS-CoV prepared by surfactant treatment or mechanical extrusion method will be a promising SARS-COV2 vaccine platform [144]. Earlier, Novavax disclosed an immunogenic composition of MERS$\mathrm{CoV}$ nanoparticle VLPs. This vaccine contains at least one trimer of the $\mathrm{S}$ protein and the proprietary adjuvant Matrix M (RN 123534117-9) capable of inducing neutralizing antibody response and protect the mice from MERS-CoV infection. Subsequently, Novavax disclosed the commencement of animal testing on potential COVID-19 vaccine candidates due to their previous experiences working with other coronaviruses, including both MERS and SARS. Their COVID-19 candidate vaccines targeting the $\mathrm{S}$ protein of SARS-CoV-2 were developed using their recombinant nanoparticle vaccine technology [145]. Pimental, et al. have designed a self-assembled a-helcial nanopeptide (about $25 \mathrm{~nm}$ ) to develop a vaccine candidate against SARS CoV. The amino acid sequence of the nanopeptide corresponds to residues $1156-1178$ on the SARS-CoV spike protein. The peptide promoted the neutralization activity of antisera in an in vitro infection inhibition assay without any adjuvants. This would be a promising platform for vaccine design against infections characterized by coiled helical epitopes as in enveloped viruses including SARS CoV2 [146]. Subunit vaccines could not make long-term memory of antigen due to weak stimulation of Thlimmune response [147]. Intranasal delivery of nanocarrier-based vaccine to experimental mice was reported to elicit antigen-specific humoral and cellular immune responses as evidenced by enhancement in co-stimulatory molecules (CD80 and CD86) , class II major histocompatibility complex molecules (I-Ad) in CD11c+ dendritic cells IFN-gamma-, TNF-alpha- and IL-2-producing cells [148]. mRNA-based prophylactic vaccine technology combines multiple mRNAs into single vaccines and mimic natural infection to elicit a more potent immune response. mRNAs encoding for viral spike proteins (full length S, S1 or S2 of SARSCoV and MERS CoV) were formulated in cationic lipid nanovesicles and designed into nanovaccines. The vaccines generate higher neutralizing antibody titre. The lipid nanoparticle with mRNA encoding the full-length $S$ protein reduced more than $90 \%$ of the viral load in the lungs of the experimental rabbits [149]. Lipid nanoparticle (LNP) -encapsulated mRNA encoding for at least one antigen of MERS-CoV were effective in eliciting immune response in mice. This was described by a patented application Yoon and Ho, 2010. We imply that one should strongly consider the ADE and gene diversity factors along with recent trends in nanotechnology and existing SARS CoV and MERS CoV vaccines for the successful and perfect design and development of SARS CoV2 vaccine. Nevertheless, the proposed and patented vaccine candidates rapidly need to be validated in clinical phases in order to ensure its immunogenic profile and safety.

\section{Targeted prevention}

Two recent systematic reviews of general practice health checks suggest that people at high risk disease may benefit from targeted prevention [150]. Older people, and people with chronic medical conditions, such as diabetes and heart disease, appear to be more at risk of developing severe symptoms of COVID-19 [151]. The approach of mask-wearing plus instant hand hygiene has been effective in preventing exponential transmission of SARS CoV2 and this approach has been reinforced by the several countries in fighting against COVID-19 pandemic [152]. Prevention of SARS CoV2 transmission among general community can be enhanced by mask 
wearing. Masks made out of advancements in nanotechnology can capture viral aerosols. For example, silver nanoparticles based fabric mask [153]. Hydrophobic masks made from nano porous silica 154 nanofibrous mask impregnated $\mathrm{TiO}_{2}$ nanoparticles and graphene oxide coated masks possess value added antiviral and virus-deactivating properties [155]. Silver nanoparticles coated to surgical mask results in enhanced antiviral effect [156]. Hand hygiene is one of the most basic yet authoritative approach to prevent the spread of COVID-19. SARS CoV2 mainly transmitted as droplets which recommends hand hygiene as a preventive measure [157]. Hand sanitizer containing silver nanoparticles sanitizer has been developed to prevent the synthesis of viral by disturbing the RNA replication and viral gemmation.

\section{Conclusion}

The entire world is showing an increasing concern about how to battle the COVID-19 pandemic and prevent such pandemics to occur in future. The properties of nanostructures in management of viral infection is rapidly revolutionizing the biomedical field. Nanobiotechnological concepts might exemplify a novel avenue to develop improvised theragnostic strategies and vaccine candidates. Translation of nanotechnological concepts into an effective theranostics and vaccines to challenge SARS-CoV2 will contribute significantly in the fight against COVID-19. We elucidated the conceptual interface between the SARS-CoV2 infection and nanotechnology which will fast-track this translational approach.

\section{Authorship information}

All authors accept direct responsibility for the manuscript.

\section{Funding information}

NA

\section{Declaration of Interest}

The authors report no conflict of interest.

\section{References}

1. Chan JFW, To KKW, Tse H, Jin DY, Yuen KY (2013) Interspecies transmission and emergence of novel viruses: Lessons from bats and birds. Trends Microbiol 21: 544555 .

2. Rota PA (2003) Characterization of a novel coronavirus associated with severe acute respiratory syndrome. Science 300: 1394-1399.

3. Cheng VCC, Lau SKP, Woo PCY, Kwok Y (2007) Severe acute respiratory syndrome coronavirus as an agent of emerging and reemerging infection. Clin Microbiol Rev 20: 660-694.

4. Savarino A, Buonavogila C, Norelli S, Trani LD, Cassone A (2006) Potential therapies for coronaviruses. Expert Opin Ther Pat 16:1269-1288.

5. Zhou P (2020) A pneumonia outbreak associated with a new coronavirus of probable bat origin. Nature 9: 221-236.

6. Peiris JSM (2003) Coronavirus as a possible cause of severe acute respiratory syndrome. Lancet 361: 1319-1325.

7. Yeung ML (2016) MERS coronavirus induces apoptosis in kidney and lung by upregulating Smad7 and FGF2. Nat Microbiol 1:16004.

8. Kim JM (2020) Identification of coronavirus isolated from a patient in Korea with covid-19. Osong Public Heal Res Perspect 11: 3-7.

9. WHO (2020) WHO Director-Generals remarks at the media briefing on 2019-nCoV on 11 February. WHO Director General's Statement.

10. Chan JFW(2020) Genomic characterization of the 2019 novel human-pathogenic coronavirus isolated from a patient with atypical pneumonia after visiting Wuhan Emerg Microbes Infect 9: 221-236.
11. Chan WCW (2020) Nano Research for COVID-19. ACS Nano 14: 3719-3720.

12. Uskoković V (2007) Nanotechnologies What we do not know. Technol Soc 29: 43-61.

13. Kostarelos K (2020) Nanoscale nights of COVID-19. Nat Nanotechnol 15: 343-344.

14. Zhang J (2020) Progress and prospects on vaccine development against sars-cov-2. Vaccines 8:153.

15. Astuti I, Ysrafil (2020) Severe Acute Respiratory Syndrome Coronavirus 2 (SARSCoV-2): An overview of viral structure and host response. Diabetes Metab Syndr Clin Res Rev 14: 407-412.

16. Jiang S, Hillyer C, Du L (2020) Neutralizing Antibodies against SARS-CoV-2 and Other Human Coronaviruses. Trends Immunol 41: 355-359.

17. Walls AC (2020) Structure, Function, and Antigenicity of the SARS-CoV-2 Spike Glycoprotein. Cell 181: 281-292.

18. Chan JFW (2020) A familial cluster of pneumonia associated with the 2019 nove coronavirus indicating person-to-person transmission: a study of a family cluster. Lancet 395: 514-523.

19. Schoeman D, Fielding BC (2019) Coronavirus envelope protein: Current knowledge. Virology J 16: 69.

20. Tai W (2020) Characterization of the receptor-binding domain (RBD) of 2019 nove coronavirus: implication for development of RBD protein as a viral attachment inhibitor and vaccine. Cell Mol Immunol 17: 613-620

21. Nasrollahzadeh M, Sajjadi M, Soufi GJ, Iravani S, Varma RS (2020) Nanomaterials and nanotechnology-associated innovations against viral infections with a focus on coronaviruses. Nanomaterials 10: 1072- 1092.

22. Singh L, Kruger HG, Maguire GEM, Govender T, Parboosing R (2017) The role of nanotechnology in the treatment of viral infections. Ther Adv Infect Dis 4:105- 131.

23. Lembo D, Cavalli R (2010) Nanoparticulate delivery systems for antiviral drugs Antiviral Chemistry and Chemotherapy 21: 53- 70.

24. Nikaeen G, Abbaszadeh S, Yousefinejad S (2020) Application of nanomaterials in treatment, anti-infection and detection of coronaviruses. Nanomedicine 15: 1501- 1512

25. Udugama B (2020) Diagnosing COVID-19: The Disease and Tools for Detection. ACS nano 14: 3822-3835.

26. Sivasankarapillai VS (2020) On facing the SARS-cov-2 (COVID-19) with combination of nanomaterials and medicine: Possible strategies and first challenges. Nanomaterials 10: $852-875$.

27. Wu C (2020) Analysis of therapeutic targets for SARS-CoV-2 and discovery of potential drugs by computational methods. Acta Pharm Sin B 10: 766- 788.

28. Chauhan G (2020) Nanotechnology for COVID-19: Therapeutics and Vaccine Research. ACS Nano 14: 7760- 7782.

29. Zhang XF, Liu ZG, Shen W, Gurunathan S (2016) Silver nanoparticles: Synthesis, characterization, properties, applications, and therapeutic approaches. Inter J Mol Sci 17: $1534-1568$

30. Akbarzadeh A (2018) An overview application of silver nanoparticles in inhibition of herpes simplex virus. Artificial Cells Nanomed Biotech 46: 263- 267.

31. Hu CMJ (2017) Nanoparticulate vacuolar ATPase blocker exhibits potent host-targeted antiviral activity against feline coronavirus. Sci Rep 7: 13043.

32. Yue H (2012) The orchestration of cellular and humoral responses is facilitated by divergent intracellular antigen trafficking in nanoparticle-based therapeutic vaccine. Pharmacol Res 65: 189- 197.

33. Coleman CM (2014) Purified coronavirus spike protein nanoparticles induce coronavirus neutralizing antibodies in mice. Vaccine 32: 3169-3174.

34. Raghuwanshi D, Mishra V, Das D, Kaur K, Suresh MR (2012) Dendritic cell targeted chitosan nanoparticles for nasal DNA immunization against SARS CoV nucleocapsid protein. Mol Pharm 9: 934- 946.

35. Chen HW (2016) Synthetic virus-like particles prepared via protein corona formation enable effective vaccination in an avian model of coronavirus infection. Biomaterials 106: $111-118$.

36. Chauhan N, Maekawa T, Kumar DNS (2017) Graphene based biosensors - Accelerating medical diagnostics to new-dimensions. J Mat Res 32: 2860- 2882.

37. Palmieri V, Papi M (2020) Can graphene take part in the fight against COVID-19? Nano Today 33: 100883. 
38. Kim H (2019) Development of Label-Free Colorimetric Assay for MERS-CoV Using Gold Nanoparticles. ACS Sensors 4: 1306- 1312.

39. Huang JC (2009) Detection of severe acute respiratory syndrome (SARS) coronavirus nucleocapsid protein in human serum using a localized surface plasmon coupled fluorescence fiber-optic biosensor. Biosens Bioelectron 25: 320- 325.

40. Roh C, Jo SK (2011) Quantitative and sensitive detection of SARS coronavirus nucleocapsid protein using quantum dots-conjugated RNA aptamer on chip. $J$ Chem Technol Biotechnol 86: 1475- 1479.

41. Ahmed SR, Kang SW, Oh S, Lee J, Neethirajan S (2018) Chiral zirconium quantum dots: A new class of nanocrystals for optical detection of coronavirus. Heliyon 4: 00766.

42. Teengam P (2017) Multiplex Paper-Based Colorimetric DNA Sensor Using Pyrrolidinyl Peptide Nucleic Acid-Induced AgNPs Aggregation for Detecting MERSCoV, MTB, and HPV Oligonucleotides. Anal Chem 89: 5428-5435.

43. Gong P (2008) Combination of functionalized nanoparticles and polymerase chain reaction-based method for SARS-CoV gene detection. J Nanosci Nanotechnol 8: 293 300 .

44. Lan FY(2020) COVID-19 symptoms predictive of healthcare workers' SARS-CoV-2 PCR results. PLoS One 15: 0235460 .

45. Cohen JP (2020) COVID-19 Image Data Collection: Prospective Predictions Are the Future. Cornell Univ 2: 1-38.

46. Rand D (2011) Nanomaterials for X-ray imaging: Gold nanoparticle enhancement of X-ray scatter imaging of hepatocellular carcinoma. Nano Lett 11: 2678-2673.

47. Rand D, Uchida M, Douglas T, Rose C (2014) X-ray spatial frequency heterodyne imaging of protein-based nanobubble contrast agents. Opt Express 22: 23290-23298.

48. Lohse S (2020) Pooling of samples for testing for SARS-CoV-2 in asymptomatic people. The Lancet Infectious Diseases 20: 1231-1232.

49. Roth WK (2019) History and Future of Nucleic Acid Amplification Technology Blood Donor Testing. Transfusion Med Hemotherapy 46: 67-75.

50. Nyazika TK (2020) Implementation of Antibody Rapid Diagnostic Testing versus Real-Time Reverse Transcription-PCR Sample Pooling in the Screening of COVID-19: a Case of Different Testing Strategies in Africa. mSphere 5: 00524-20.

51. Zhu N (2020) A novel coronavirus from patients with pneumonia in China 2019. N Engl J Med 382: 727-733.

52. Ahn DG (2020) Current status of epidemiology, diagnosis, therapeutics, and vaccines for novel coronavirus disease 2019 (COVID-19). J Microbiol Biotechnol 30: 313-324.

53. Yuan W (2015) Development of a nanoparticle-assisted PCR assay for detection of porcine epidemic diarrhea virus. $J$ Virol Methods 220: 18-20.

54. Zhu Y (2017) A sensitive duplex nanoparticle-assisted PCR assay for identifying porcine epidemic diarrhea virus and porcine transmissible gastroenteritis virus from clinical specimens. Virus Genes 53: 71-76.

55. Park TJ (2006) Protein nanopatterns and biosensors using gold binding polypeptide as a fusion partner. Anal Chem 78: 7197-7225.

56. Qiu G (2020) Dual-Functional Plasmonic Photothermal Biosensors for Highly Accurate Severe Acute Respiratory Syndrome Coronavirus 2 Detection. ACS Nano 14: 5268-5277.

57. Bian H (2019) A new immunochromatographic assay for on-site detection of porcine epidemic diarrhea virus based on monoclonal antibodies prepared by using cell surface fluorescence immunosorbent assay. BMC Vet Res 15: 1773-1774.

58. Layqah LA, Eissa S (2019) An electrochemical immunosensor for the corona virus associated with the Middle East respiratory syndrome using an array of gold nanoparticle-modified carbon electrodes. Microchim Acta 186: 224-228.

59. Seo G (2020) Rapid Detection of COVID-19 Causative Virus (SARS-CoV-2) in Human Nasopharyngeal Swab Specimens Using Field-Effect Transistor-Based Biosensor. ACS Nano 14: 5135-5142.

60. Xiang J (2020) Evaluation of Enzyme-Linked Immunoassay and Colloidal GoldImmunochromatographic Assay Kit for Detection of Novel Coronavirus (SARSCov-2) Causing an Outbreak of Pneumonia (COVID-19). CSH BMJ.

61. Hill HD, Mirkin CA (2006) The bio-barcode assay for the detection of protein and nucleic acid targets using DTT-induced ligand exchange. Nat Protoc 1: 324-336.

62. Kim J, Biondi MJ, Feld JJ, Chan WCW (2016) Clinical Validation of Quantum Dot Barcode Diagnostic Technology. ACS Nano 5: 1580-1587.
63. Thaxton CS (2009) Nanoparticle-based bio-barcode assay redefines 'undetectable' PSA and biochemical recurrence after radical prostatectomy. Proc Natl Acad Sci USA 106: $18437-18442$.

64. Sheridan C (2020) Convalescent serum lines up as first-choice treatment for coronavirus. Nature Biotechnol 38: 655-658.

65. Tian X (2020) Potent binding of 2019 novel coronavirus spike protein by a SARS coronavirus-specific human monoclonal antibody. Emerging Microbes and Infections 9: $382-385$.

66. Wang C (2020) A human monoclonal antibody blocking SARS-CoV-2 infection. Nat Commun 11: 2251.

67. Gagnee JF, Deesormeaux A, Perron S, Tremblay MJ, Bergeron MG (2002) Targeted delivery of indinavir to HIV-1 primary reservoirs with immunoliposomes. Biochim Biophys Acta Biomembr 1558: 198-210.

68. Hamers C (1993) Naturally occurring antibodies devoid of light chains. Nature 363 446-448.

69. Muyldermans S (2013) Nanobodies: Natural single-domain antibodies. Annual Rev Biochem 82: 775-797.

70. Tarr AW (2013) An alpaca nanobody inhibits hepatitis C virus entry and cell-to-cell transmission. Hepatology 58: 932-939.

71. Keyaerts E (2009) Antiviral activity of chloroquine against human coronavirus OC43 infection in newborn mice. Antimicrob Agents Chemother 53: 3416-3421.

72. Keyaerts E, Vijgen L, Maes P, Neyts J, Ranst M (2004) In vitro inhibition of severe acute respiratory syndrome coronavirus by chloroquine. Biochem Biophys Res Commun 323: $264-268$

73. Wolfram J, Ferrari M (2019) Clinical cancer nanomedicine. Nano Today 25: 85-98.

74. Hu TY, Frieman M, Wolfram J (2020) Insights from nanomedicine into chloroquine efficacy against COVID-19. Nature Nanotechnol 15: 247-249.

75. Wolfram J (2017) A chloroquine-induced macrophage-preconditioning strategy for improved nanodelivery. Sci Rep 7: 13738.

76. Miller SE (2015) CALM Regulates Clathrin-Coated Vesicle Size and Maturation by Directly Sensing and Driving Membrane Curvature. Dev Cell 33: 163-175.

77. Hattori Y (2019) Effect of cationic lipid type in PEGylated liposomes on siRNA delivery following the intravenous injection of siRNA lipoplexes. World Acad Sci J 8: $74-85$

78. Frieman M (2007) Severe Acute Respiratory Syndrome Coronavirus ORF6 Antagonize STAT1 Function by Sequestering Nuclear Import Factors on the Rough Endoplasmic Reticulum/Golgi Membrane. J Virol 81: 9812-9824.

79. Caly L, Druce JD, Catton MG, Jans DA, Wagstaff KM (2020) The FDA-approved drug ivermectin inhibits the replication of SARS-CoV-2 in vitro. Antiviral Res 178: 104787.

80. Ahmadpour E (2019) Nanostructured lipid carriers of ivermectin as a novel drug delivery system in hydatidosis. Parasites and Vectors 12: 469.

81. Gyebi GA, Ogunro OB, Adegunloye AP, Ogunyemi OM, Afolabi SO (2020) Potential inhibitors of coronavirus 3-chymotrypsin-like protease (3CLpro): an in silico screening of alkaloids and terpenoids from African medicinal plants. J Biomol Struct Dyn 0739: 110.

82. Kandeel M, AlTaher A, Park BK, Kwon HJ, AlNazawi M (2020) A Pilot Study of the Antiviral Activity of Anionic and Cationic Polyamidoamine Dendrimers Against the Middle East Respiratory Syndrome Coronavirus. J Med Virol 92: 1665-1670.

83. Ellah NHA, Tawfeek HM, John J, Hetta HF (2019) Nanomedicine as a future therapeutic approach for Hepatitis C virus. Nanomedicine 14: 11.

84. Garrido C (2015) Gold nanoparticles to improve HIV drug delivery. Future Med Chem 7: $1097-1107$.

85. Ogunwuyi O (2016) Antiretroviral Drugs-Loaded Nanoparticles Fabricated by Dispersion Polymerization with Potential for HIV/AIDS Treatment. Infect Dis Res Treat 9: 21-32.

86. Smith KA (2015) Activation of HIV-1 with nanoparticle-packaged small-molecule protein phosphatase-1-targeting compound. Sci Pharm 83: 535-548.

87. Jahangirian $\mathrm{H}$ (2019) A review of small molecules and drug delivery applications using gold and iron nanoparticles. Int J Nanomedicine 14:1633-1657.

88. Arya R, Das A, Prashar V, Kumar M (2020) Potential Inhibitors Against Papain-like Protease of Novel Coronavirus (COVID-19) from FDA Approved Drugs. ChemRxivx. 
89. Thi THH, Azaroual N, Flament MP (2009) Characterization and in vitro evaluation of the formoterol/cyclodextrin complex for pulmonary administration by nebulization. Eur J Pharm Biopharm 72: 214-218.

90. Kaur G, Narang RK, Rath G, Goyal AK (2012) Advances in pulmonary delivery of nanoparticles. Artificial Cells Blood Substitutes Biotechnol 40: 75-96.

91. Kuzmov A, Minko T (2015) Nanotechnology approaches for inhalation treatment of lung diseases. J Control Release 219: 500-518.

92. Me M (2018) Cytotoxicity of 6-Mercaptopurine via Loading on PVA-Coated Magnetite Nanoparticles Delivery System: A New Era of Leukemia Therapy. J Nanomed Nanotechnol 9: 6

93. GrabowskaJadach I, Drozd M, Kulpinska D, Komendacka K, Pietrzak M (2020) Modification of fluorescent nanocrystals with 6-thioguanine: monitoring of drug delivery. Appl Nanosci 8: 309-321.

94. NezhadMokhtari P, Ghorbani M, Mahmoodzadeh F (2019) Smart co-delivery of 6-mercaptopurine and methotrexate using disulphide-based PEGylated-nanogels for effective treatment of breast cancer. New J Chem 43: 121559-12167.

95. Decroly E (2008) Coronavirus Nonstructural Protein 16 Is a Cap-0 Binding Enzyme Possessing (Nucleoside-2O)-Methyltransferase Activity. J Virol 82: 8071-8075.

96. Khan RJ (2020) Targeting SARS-CoV-2: a systematic drug repurposing approach to identify promising inhibitors against $3 \mathrm{C}$-like proteinase and 2'-O-ribose methyltransferase. J Biomol Struct Dyn 0739:1102.

97. Sillman B (2018) Creation of a long-acting nanoformulated dolutegravir. Nat Commun 9: 443 .

98. Mandal S, Prathipati PK, Belshan M, Destache CJ (2019) A potential long-acting bictegravir loaded nano-drug delivery system for HIV-1 infection: A proof-of-concept study. Antiviral Res 167:83-87.

99. Lee C (2009) Investigation of the pharmacophore space of Severe Acute Respiratory Syndrome coronavirus (SARS-CoV) NTPase/helicase by dihydroxychromone derivatives. Bioorganic Med Chem Lett 19: 4538-4544.

100. Chen R (2010) Bismuth subcarbonate nanoparticles fabricated by water-in-oil microemulsion-assisted hydrothermal process exhibit anti-Helicobacter pylori properties. Mater Res Bull 45: 654-658.

101. Shu T (2020) SARS-Coronavirus-2 Nsp13 Possesses NTPase and RNA Helicase Activities That Can Be Inhibited by Bismuth Salts. Virol Sin 35: 321-329.

102. Kang B, Mackey MA, ElSayed MA (2010) Nuclear targeting of gold nanoparticles in cancer cells induces DNA damage, causing cytokinesis arrest and apoptosis. $J \mathrm{Am}$ Chem Soc 95: 3735-3741.

103. Datta A, Brosh RM (2018) New insights into DNA helicases as druggable targets for cancer therapy. Frontiers Molecular Biosci 5: 59.

104. Loretz B, Foger F, Werle M, Bernkop A (2006) Oral gene delivery: Strategies to improve stability of pDNA towards intestinal digestion. J Drug Target 14: 311-319.

105. ODriscoll CM, Bernkop A, Friedl JD, Preat V, Jannin V (2019) Oral delivery of non-viral nucleic acid-based therapeutics - do we have the guts for this. Eur J Pharm Sci 133: 190-224.

106. Pachetti M (2020) Emerging SARS-CoV-2 mutation hot spots include a novel RNAdependent-RNA polymerase variant. J Transl Med 18: 179

107. Sungnak W (2020) SARS-CoV-2 entry factors are highly expressed in nasal epithelia cells together with innate immune genes. Nat Med 26: 681-687.

108. Bittmann S, Alieva EM, Weissenstein A, Luchter E (2020) The role of TMPRSS2Inhibitor Camostat in the pathogenesis of COVID-19 in lung. Cell 1:20875-20877.

109. Hoffmann M (2020) SARS-CoV-2 Cell Entry Depends on ACE2 and TMPRSS2 and Is Blocked by a Clinically Proven Protease Inhibitor. Cell 181: 271-280.

110. Yin J, Noda Y, Yotsuyanagi T (2006) Properties of poly(lactic-co-glycolic acid) nanospheres containing protease inhibitors: Camostat mesilate and nafamostat mesilate. Int J Pharm 314: 46-55.

111. Chenthamara D (2019) Therapeutic efficacy of nanoparticles and routes of administration. Biomaterials Res 23: 20 .

112. Zhang L, Pornpattananangkul D, Hu CM, Huang CM (2010) Development of Nanoparticles for Antimicrobial Drug Delivery. Curr Med Chem 17: 585-594.

113. Krolevets AA (2006) Method for producing nanocapsules of umifenovir (arbidol) in carrageenan. Patent
114. Wu D, Wu T, Liu Q, Yang Z (2020) The SARS-CoV-2 outbreak: What we know. Int J Infectious Dis 94: 44-48.

115. Wiley JA (2009) Inducible bronchus-associated lymphoid tissue elicited by a protein cage nanoparticle enhances protection in mice against diverse respiratory viruses. PLoS One 4: 7142

116. Quinton LJ (2012) Leukemia Inhibitory Factor Signaling Is Required for Lung Protection during Pneumonia. J Immunol 188: 6300-6308.

117. Metcalfe SM (2020) COVID-19 lockdown: de-risking exit by protecting the lung with leukaemia inhibitory factor (LIF). Med Drug Discov 6: 100043.

118. Metcalfe SM, Strom TB, Williams A, Fahmy TM (2015) Multiple Sclerosis and the LIF/IL-6 Axis: Use of Nanotechnology to Harness the Tolerogenic and Reparative Properties of LIF. Nanobiomedicine 2: 5 .

119. Mehta P (2020) COVID-19: consider cytokine storm syndromes and immunosuppression. The Lancet 395: 1033-1034.

120. Dormont $F$ (2020) Squalene-based multidrug nanoparticles for improved mitigation of uncontrolled inflammation in rodents. Sci $A d v$ 6: 5666.

121. Maudens P, Seemayer CA, Pfefferle F, Jordan O, Allemann E (2018) Nanocrystals of a potent $\mathrm{p} 38$ MAPK inhibitor embedded in microparticles: Therapeutic effects in inflammatory and mechanistic murine models of osteoarthritis. J Control Release 276: $102-112$.

122. Bains BK (2016) Encapsulation of the p38 MAPK inhibitor GSK 678361A in nanoparticles for inflammatory-based disease states. J Interdiscip Nanomedicine 3: 4

123. Jang Y (2018) Salinomycin Inhibits Influenza Virus Infection by Disrupting Endosomal Acidification and Viral Matrix Protein 2 Function. $J$ Virol 92: 01441.

124. Pindiprolu SKSS (2020) Pulmonary delivery of nanostructured lipid carriers for effective repurposing of salinomycin as an antiviral agent. Med Hypotheses 143: 109858.

125. Ye S (2015) Antiviral Activity of Graphene Oxide: How Sharp Edged Structure and Charge Matter. ACS Appl Mater Interfaces 7: 21571-21579.

126. Chen YN, Hsueh YH, Hsieh C, Te, Tzou DY, Chang PL (2016) Antiviral activity of graphene-silver nanocomposites against non-enveloped and enveloped viruses. Int $J$ Environ Res Public Health 13: 430.

127. Zhou Y (2020) High antiviral activity of mercaptoethane sulfonate functionalized Te/BSA nanostars against arterivirus and coronavirus. RSC Adv 10: 14161-14169.

128. Vizirianakis IS (2011) Nanomedicine and personalized medicine toward the application of pharmacotyping in clinical practice to improve drug-delivery outcomes. Nanomedicine Nanotechnol Biol Med 7: 11-17.

129. Wang LY (2020) Genetic Profiles in Pharmacogenes Indicate Personalized Drug Therapy for COVID-19. MedRxiv.

130. Amanatiadou ISV, EP (2012) Pharmacogenomics and Nanotechnology Toward Advancing Personalized Medicine. Nanosci Technol 6: 115-134.

131. Marchant G (2012) Small is Beautiful: What Can Nanotechnology Do for Personalized Medicine? Curr Pharmacogenomics Person Med 7: 231-237.

132. Kruse RL (2020) Therapeutic strategies in an outbreak scenario to treat the novel coronavirus originating in Wuhan, China. F1000Research 9: 72.

133. Jiang S, Du L, Shi Z (2020) An emerging coronavirus causing pneumonia outbreak in Wuhan, China: calling for developing therapeutic and prophylactic strategies. Emerging Microbes and Infections 9: 275-277.

134. Mullard A (2020) COVID-19 vaccine development pipeline gears up. Lancet London England 395: 1751-1752.

135. Martin JE (2008) A SARS DNA vaccine induces neutralizing antibody and cellular immune responses in healthy adults in a Phase I clinical trial. Vaccine 26: 6338-6343.

136. Okba NM, Raj VS, Haagmans BL (2017) Middle East respiratory syndrome coronavirus vaccines: current status and novel approaches. Curr Opinion Virology 23: 49-58.

137. Tirado SMC, Yoon KJ (2003) Antibody-dependent enhancement of virus infection and disease. Viral Immunol 16: 69-86.

138. Khandia R (2018) Modulation of Dengue/Zika Virus pathogenicity by antibodydependent enhancement and strategies to protect against enhancement in Zika Virus infection. Frontiers Immunol 9: 597. 
139. Wan Y (2019) Molecular Mechanism for Antibody-Dependent Enhancement of Coronavirus Entry. J Virol 75: 2324-2330.

140. Wang SF (2014) Antibody-dependent SARS coronavirus infection is mediated by antibodies against spike proteins. Biochem Biophys Res Commun 451: 208-214.

141. Kim TW (2004) Generation and Characterization of DNA Vaccines Targeting the Nucleocapsid Protein of Severe Acute Respiratory Syndrome Coronavirus. J Virol 78: 4638-4645.

142. Malathi B, Mona S, Thiyagarajan D, Kaliraj P (2015) Immunopotentiating nanochitosan as potent vaccine carter for efficacious prophylaxis of filarial antigens. Int $J$ Biol Macromol 73: 131-137.

143. Coleman CM (2017) MERS-CoV spike nanoparticles protect mice from MERS-CoV infection. Vaccine 35: 1586-1589.

144. Kato T, Takami Y, Kumar V, Park EY (2019) Preparation of virus-like particle mimetic nanovesicles displaying the $\mathrm{S}$ protein of Middle East respiratory syndrome coronavirus using insect cells. J Biotechnol 306: 177-184.

145. Liu C (2020) Research and Development on Therapeutic Agents and Vaccines for COVID-19 and Related Human Coronavirus Diseases. ACS Cent Sci 6: 315-331.

146. Pimentel TAPF (2009) Peptide nanoparticles as novel immunogens: Design and analysis of a prototypic severe acute respiratory syndrome vaccine. Chem Biol Drug Des 73: 53-61.

147. Naz RK, Dabir P (2007) Peptide vaccines against cancer, infectious diseases, and conception. Frontiers Biosci 12: 1833-1844.
148. Yoon CHCJ (2010) SARS vaccine nano-delivery system. Patent 0120473: 1-10.

149. Liu C (2019) A boronic acid-rich dendrimer with robust and unprecedented efficiency for cytosolic protein delivery and CRISPR-Cas9 gene editing. Sci Adv 5: 8922.

150. Si S, Moss JR, Sullivan TR, Newton SS, Stocks NP (2014) Effectiveness of general practice-based health checks: A systematic review and meta-analysis. British $J$ General Pract 64: 47-53.

151. Noh JY (2020) Social distancing against COVID-19: Implication for the control of influenza. J Korean Med Sci 35: 182.

152. Ma QX (2020) Potential utilities of mask-wearing and instant hand hygiene for fighting SARS-CoV-2. J Med Virol 92: 1567-1572.

153. Joe YH, Park DH, Hwang J (2016) Evaluation of Ag nanoparticle coated air filter against aerosolized virus: Anti-viral efficiency with dust loading. J Hazard Mater 301: $547-553$

154. ElAtab N (2020) Flexible Nanoporous Template for the Design and Development of Reusable Anti-COVID-19 Hydrophobic Face Masks. ACS Nano 14:7659-7665.

155. Konda A (2020) Aerosol Filtration Efficiency of Common Fabrics Used in Respiratory Cloth Masks. ACS Nano 14: 6339-6347.

156. Li Y, Leung P, Yao L, Song QW, Newton E (2006) Antimicrobial effect of surgical masks coated with nanoparticles. J Hosp Infect 62: 58-63.

157. Stadnytskyi V, Bax CE, Bax A, Anfinrud P (2020) The airborne lifetime of small speech droplets and their potential importance in SARS-CoV-2 transmission. Proc Natl Acad Sci USA (2020).

Copyright: (C2021 Devasena T. This is an open-access article distributed under the terms of the Creative Commons Attribution License, which permits unrestricted use, distribution, and reproduction in any medium, provided the original author and source are credited. 